\title{
Highly purified, multi-wall carbon nanotubes induce light-chain 3B expression in human lung cells
}

\author{
Tamotsu Tsukahara ${ }^{1 *}$, Yoshikazu Matsuda ${ }^{2}$, Yuki Usui ${ }^{3}$ and Hisao Haniu ${ }^{4}$ \\ ${ }^{1}$ Department of Hematology and Immunology, Kanazawa Medical University, 1-1 Daigaku, \\ Uchinada, Ishikawa 920-0293, Japan \\ ${ }^{2}$ Clinical Pharmacology Educational Center, Nihon Pharmaceutical University, Ina-machi, Saitama \\ 362-0806, Japan \\ ${ }^{3}$ Research Center for Exotic Nanocarbons, Shinshu University, 4-17-1 Wakasato, Nagano-shi, Nagano, \\ 380-8553, Japan \\ ${ }^{4}$ Department of Orthopaedic Surgery, Shinshu University School of Medicine, 3-1-1 Asahi, \\ Matsumoto, Nagano 390-8621, Japan
}

* Author to whom correspondence should be addressed; E-mail: ttamotsu@ kanazawa-med.ac.jp Department of Hematology and Immunology, Kanazawa Medical University, 1-1 Daigaku, Uchinada, Ishikawa 920-0293, Japan

Short title: Autophagic cell death induced by HTT2800

\begin{abstract}
Bronchial epithelial cells are targets of inhalation and play a critical role in the maintenance of mucosal integrity as mechanical barriers against various particles. Our previous result suggest that vapor-grown carbon fiber, HTT2800, which is one of the most highly purified multi-wall carbon nanotubes (MWCNT) showed cellular uptake of the carbon nanotube, increased cell death, enhanced DNA damage, and induced cytokine release. Increasing evidence suggests that autophagy may critically influence vital cellular processes such as apoptosis, cell proliferation and inflammation and thereby may play a critical role in pulmonary diseases. Autophagy was recently recognized as a critical cell death pathway, and autophagosome accumulation has been found to be associated with the exposure of various nanoparticles. In this study, the authors focus on the autophagic responses of HTT2800 exposure. The HTT2800-exposed cells induced LC3B expression and induced cell growth inhibition.
\end{abstract}

Keywords: Bronchial epithelial cells; Carbon nanotube; Autophagy; LC3B 


\section{Introduction}

Several studies report that nanoparticles have been functionalized to improve their biocompatibility and to promote their interaction with biomolecules.[1,2,3] The discovery of carbon nanotubes has greatly advanced this area because of their peculiar structures and properties.[4] Interestingly, Flahaut et al. synthesized carbon nanotubes by catalytic chemical vapor deposition that were nontoxic to human cells.[5] Unpurified carbon nanotubes have been are reportedly more toxic than metal-free nanoparticles. The iron catalyst was removed from the vapor-grown carbon fiber HTT2800 by thermally treating the material at a temperature of $2,800^{\circ} \mathrm{C}$ in an $\arg$ on atmosphere.[6] This suggests that only a very low concentration of iron-based material remains in HTT2800. Our previous results suggested that HTT2800, which is one of the most highly purified multi-wall carbon nanotubes (MWCNT), showed cellular uptake of the carbon nanotube, increased cell death, enhanced DNA damage, and induced cytokine release.[6] However, information regarding the existing pulmonary impacts of HTT2800 is limited and remains inconclusive. A recent study suggested that nanoparticles are emerging as a novel class of autophagy-inducers.[7] Autophagy, which was first described in $1963,[8]$ is a tightly regulated cellular process involving bulk cytoplasmic and organelle degradation.[9,10,11] Common to nearly all eukaryotes, autophagy is a lysosomal degradation pathway that recycles intracellular components such as protein aggregates and damaged or dysfunctional intracellular organelles.[12,13] Autophagy was recently recognized as a critical cell death pathway, and autophagosome accumulation was found to be associated with exposure to various nanoparticles.[14] However, the detailed mechanisms of their interaction with cells remain unclear. In this study, we investigated autophagy in BEAS-2B cells by assessing the expression of the autophagic marker light-chain 3B (LC3B) and its effects on cell death and proliferation.

\section{Materials and Methods}

\subsection{Reagents}

We used highly purified MWCNT known as HTT2800, which was previously described in detail.[15] HTT2800 was dispersed in $0.1 \%$ gelatin (Nacalai Tesque, Kyoto, Japan) in phosphatebuffered saline (PBS, pH 7.4) and was ultrasonicated before use. Tissue culture media were obtained from Sigma Aldrich (St. Louis, MO, USA). E-64d and pepstatin A were purchased from the Peptide Institute (Osaka, Japan), brefeldin A was obtained from Cell Signaling Technology (Danvers, MA, USA). 3-MA and z-VAD-FMK were purchased from Santa Cruz Biotechnology (Santa Cruz, CA, USA). Rabbit monoclonal LC3B antibody was purchased from Cell Signaling Technology (Danvers, MA, USA). Premo ${ }^{\mathrm{TM}}$ Autophagy Sensor (LC3B-FP) was purchased from Molecular Probes (Eugene, OR, USA).

\subsection{Cell culture}

BEAS-2B cells were purchased from the American Type Culture Collection (Manassas, VA, USA). Cells were maintained in Dulbecco's modified Eagle's medium (DMEM) containing 10\% fetal bovine 
serum (FBS), penicillin (100 U/mL), and streptomycin $(100 \mu \mathrm{g} / \mathrm{mL})$. Cells were grown and maintained in $100-\mathrm{mm}$ culture plates (Iwaki, Tokyo, Japan) at $37^{\circ} \mathrm{C}$ in a $5 \% \mathrm{CO}_{2}$ incubator.

\subsection{Western blot analysis}

BEAS-2B cells were treated with HTT2800 for the indicated time periods. Cells were washed 2 times with ice-cold PBS and solubilized in whole-cell extraction buffer (20 mM 4-(2-hydroxyethyl)-1piperazineethanesulfonic acid (HEPES, pH 7.9), 0.5\% Nonidet P-40 (NP-40), 15\% glycerol, $300 \mathrm{mM}$ $\mathrm{NaCl}, 1 \mathrm{mM}$ ethylenediaminetetraacetic acid (EDTA), $10 \mathrm{mM} \mathrm{NaF}, 1 \mathrm{mM} \mathrm{Na} \mathrm{VO}_{4}, 1 \mathrm{mM}$ dithiothreitol (DTT), $1 \mu \mathrm{g} / \mathrm{mL}$ leupeptin, $1 \mu \mathrm{g} / \mathrm{mL}$ pepstatin, $1 \mu \mathrm{g} / \mathrm{mL}$ aprotinin, and $0.5 \mathrm{mM}$ phenylmethanesulfonyl fluoride (PMSF)). The cell lysate was centrifuged at $14,000 \times g$ for $5 \mathrm{~min}$, and the protein in the supernatant was quantified using Bradford protein assay reagent (Bio-Rad, Hercules, CA, USA). Total protein was diluted 1:4 with lane marker reducing sample buffer (Thermo Fisher Scientific, Waltham, MA, USA) and boiled for $5 \mathrm{~min}$. The resultant protein was then separated by $5-$ $20 \%$ sodium dodecyl sulfate-polyacrylamide gel electrophoresis (SDS-PAGE) and transferred to a polyvinylidene fluoride (PVDF) membrane (GE Healthcare, Little Chalfont, UK). The membrane was blocked with 5\% skim milk in Tris-buffered saline (TBS) with $0.1 \%$ Tween 20 (pH 7.6) for $1 \mathrm{~h}$ at room temperature and probed with primary rabbit LC3B antibody (Cell Signaling Technology, Danvers, MA, USA) and caspase-3 antibody (Santa Cruz Biotechnology) at $4^{\circ} \mathrm{C}$ overnight. After washing, the membrane was incubated with the secondary horseradish peroxidase-linked speciesspecific whole antibody (anti-rabbit or anti-mouse IgG; GE Healthcare) for $1 \mathrm{~h}$ at room temperature and visualized using EzWestLumi plus (ATTO, Tokyo, Japan).

\subsection{Quantitative real-time PCR analysis}

Total RNA was prepared from BEAS-2B cells using NucleoSpin ${ }^{\circledR}$ RNA II (Takara). cDNA was then synthesized using $0.5 \mu \mathrm{g}$ of total RNA and the ReverTra Ace qPCR RT Kit (Toyobo, Osaka, Japan) according to the manufacturer's instructions. mRNA levels were quantified using an ECO Real-Time PCR system (Illumina, Inc., San Diego, CA, USA) and SYBR Green Realtime PCR Master Mix-Plus(Toyobo) with the following primer pair sets: LC3B, 5'-GAGAAGCAGCTTCCTGTTCTGG-3' (F) and 5'-GTGTCCGTTCACCAACAGGAAG-3' (R); and 18S rRNA, 5'CAGCCACCCGAGATTGAGCA-3' (F) and 5'-TAGTAGCGACGGGCGGTGTG-3' (R). All reactions were performed in a $10-\mu \mathrm{L}$ volume using 48 -well PCR plates (Illumina). Cycling conditions were $95^{\circ} \mathrm{C}$ for $10 \mathrm{~min}$ (polymerase activation), followed by 40 cycles of $95^{\circ} \mathrm{C}$ for $15 \mathrm{~s}, 55^{\circ} \mathrm{C}$ for $15 \mathrm{~s}$, and $72^{\circ} \mathrm{C}$ for $30 \mathrm{~s}$. To determine which housekeeping genes were most suitable for subsequent normalization of data, we initially selected 3 candidates, GAPDH, $\beta$-actin, and 18S-rRNA, which are commonly used as internal controls in mammalian cells. After amplification, the samples were slowly heated from $55^{\circ} \mathrm{C}$ to $95^{\circ} \mathrm{C}$ with continuous reading of fluorescence to obtain a melting curve. The

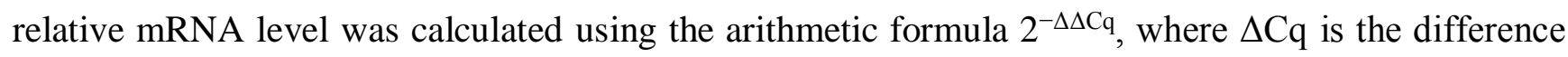
between the threshold cycle of a given target cDNA and an endogenous reference cDNA. Derivations of the formulas and validation tests are described in the Applied Biosystems User Bulletin No. 2. 


\subsection{Cell viability assay}

BEAS-2B cells $\left(5 \times 10^{3}\right)$ were seeded into each well of 96-well tissue culture plates, cultured for $24 \mathrm{~h}$, and incubated for $24 \mathrm{~h}$ with various concentrations of HTT2800 before cell viability was determined using the Cell Counting Kit-8 (CCK-8; Dojindo, Kumamoto, Japan). Briefly, $10 \mu \mathrm{L}$ of CCK-8 solution was added to the medium and incubated for $2 \mathrm{~h}$ in an incubator with a $5 \% \mathrm{CO}_{2}$ atmosphere. The amount of orange formazan dye that was produced was calculated by measuring the absorbance at 450 $\mathrm{nm}$ in a microplate reader (Awareness Technology, Inc., Palm City, FL, USA).

\subsection{Autophagy detection}

For autophagy and lysosomal protease inhibitor studies, BEAS-2B cells were pretreated for $3 \mathrm{~h}$ with the caspase inhibitor $\mathrm{z}-\mathrm{VAD}-\mathrm{FMK}(20 \mu \mathrm{M})$ the endosomal trafficking inhibitor brefeldin $\mathrm{A}(20 \mu \mathrm{M})$, the autophagy inhibitor 3-methyladenine (3-MA, $100 \mu \mathrm{M})$, and the lysosomal protease inhibitors E64$\mathrm{d}(10 \mu \mathrm{g} / \mathrm{mL})$ and pepstatin $\mathrm{A}(20 \mu \mathrm{M})$. Cells were then co-incubated with the compounds and HTT2800 for a further $3,6,12$, or $24 \mathrm{~h}$ before the cell viability was evaluated using the CCK-8. Autophagosomes were detected by monitoring the cellular distribution of GFP-LC3BII using GFPLC3B (LC3B-FP) provided by Premo ${ }^{\mathrm{TM}}$ Autophagy Sensors. Mutated GFP-LC3BII (G120A) was used as a negative control. BEAS-2B cells were plated at $5 \times 10^{3}$ cells/well. Cells were then transduced with LC3B-GFP. Twenty-four hours later, the cells were incubated with HTT2800 with or without 3-MA $(10,30$, and $100 \mu \mathrm{M})$ for $24 \mathrm{~h}$. Analysis was performed by quantifying the florescence from vesicular structures in the perinuclear region using an Olympus fluorescent microscope IX73 (Tokyo, Japan).

\subsection{Measurement of ROS}

The reactive oxygen species (ROS) assay was performed according to the manufacturer's instructions. Briefly, BEAS-2B cells were seeded in 12-well plates at a density of $5 \times 10^{4}$ cells/well and incubated at $37^{\circ} \mathrm{C}$ for $24 \mathrm{~h}$. Next, the culture medium was aspirated and cells were washed with Dulbecco PBS (-) (DPBS) followed by the addition of $1 \mathrm{~mL}$ of fresh culture medium containing $10 \mu \mathrm{M}$ carboxy-DCFDA (C-400, Molecular Probes) dissolved in dimethylsulfoxide (DMSO). After the cells were incubated for $15 \mathrm{~min}$ in a $\mathrm{CO}_{2}$ incubator, $10 \mu \mathrm{L}$ of test solution was added to the cells. Hydrogen peroxide $(1 \mathrm{mM})$ was used as a positive control stimulus. Following exposure for $60 \mathrm{~min}$, the cells were washed once with DPBS and harvested with trypsin-EDTA. Finally, the cells were suspended with $0.3 \mathrm{~mL}$ of $10 \%$ FBS in DPBS and passed through a nylon mesh. Cells were subjected to flow cytometry (FACSCaliburTM, Becton Dickinson, Franklin Lakes, NJ, USA) until 20,000 events were recorded.

\subsection{Statistical analysis}

Data are presented as the mean \pm standard error of the mean (SEM). Values were compared and analyzed using Student's $t$-test. We considered P-values less than 0.05 to be statistically significant. 


\section{Results and Discussion}

We used LC3B as a marker of autophagosome formation. Our major finding in this study is that HTT2800-induced autophagosome formation in BEAS-2B cells enhanced LC3B expression. First, we examined the expression of LC3B mRNA and protein in BEAS-2B cells after treatment with HTT2800 $(10 \mu \mathrm{g} / \mathrm{mL})$. As shown in Fig. 1A, cells were cultured for $24 \mathrm{~h}$ in nutrient-rich conditions. Interestingly, there was a dose-dependent increase in LC3B mRNA expression in BEAS-2B cells. Furthermore, expression levels of LC3B-II protein agreed with those of mRNA levels (Fig. 1B). These results suggest that HTT2800-treated BEAS-2B cells induced LC3B in a time-dependent manner. The effect of HTT2800 on BEAS-2B cell viability was evaluated using the CCK-8 assay. As shown in Fig. 2A and B, HTT2800-treated BEAS-2B cells showed decreased cell proliferation that was both timeand dose-dependent. As shown in Fig.3A and B, following addition of 3-MA, LC3B-II protein and mRNA levels were significantly decreased. Next, to determine whether endocytosis and lysosomal regulation are involved in HTT2800-induced cell death, cells were pretreated for $2 \mathrm{~h}$ with brefeldin A, which inhibits the transport of proteins from the endoplasmic reticulum (ER) to the Golgi, 3-MA, which inhibits autophagosome formation, or E64-d and pepstatin A, which are lysosomal proteinase inhibitors, prior to HTT2800 treatment. As shown in Fig. 3C and D, GFP-LC3B cellular localization was determined by confocal microscopy. Following addition of 3-MA, the number of vacuoles was lower than in the HTT2800-treated group. Next, as shown in Fig. 3E, 3-MA and E64-d+pepstatin A, but not brefeldin A, provided protection against HTT2800-induced cell death of BEAS-2B cells that occurred via the autophagic rather than the endocytic pathway. Autophagic cell death is characterized by the massive accumulation of autophagic vacuoles in the cytoplasm of cells that lack signs of apoptosis.[16] Because activation of the caspase signaling pathway is not always observed in autophagic cell death, we examined whether it was involved in HTT2800-mediated cell death. Our previous observations indicated that HTT2800 did not induce the common apoptotic fragmentation of caspase-3.[6] As shown in Fig. 4A, z-VAD-FMK failed to suppress HTT2800-induced cell death. Furthermore, we examined the cleavage of caspase-3. Interestingly, compared to control, cleaved caspase-3 was increased after treatment with 3-MA (Fig. 4B). This result further supported the hypothesis that caspase-3 is not involved in the mechanism of HTT2800-induced cell death in BEAS2B cells. Next, airway epithelial cells are at risk for damage after inhaling ROS, which are present in many environmental particulates.[17] Oxidative damage due to ROS results in damage to DNA, proteins, and lipids and the activation of cell-signaling pathways that is associated with the loss of cell growth regulation.[18] However, by measuring ROS production upon HTT2800 exposure, there was no significant difference after short-term exposure (60 min) (Fig. 4C). Our previous results also suggested that no obvious 2,7-dichlorofluorescin diacetate (DCF, a ROS indicator) response was observed after 24-h exposure to HTT2800 at concentrations between 0.1 and $30 \mu \mathrm{g} / \mathrm{mL}$. [6] Taken together, these results suggest that HTT2800-induced cell death occurred via the caspase- and ROSindependent pathways. It has been reported that autophagosome induction from nanomaterial treatment is associated with cell death.[19] In fact, nanomaterials were observed within the autophagosome compartment.[20] To investigate autophagy in BEAS-2B cells, we used LC3B as a marker of autophagy. When autophagy is not activated, LC3B is localized to the cytoplasm. However, upon initiation of autophagy under cellular stress, LC3B associates with the isolation membrane. Cleavage 
of LC3B at the carboxyl terminus immediately following synthesis yields the cytosolic form of LC3BI. During autophagy, LC3B-I is converted to LC3B-II through lipidation by autophagy-related genes (Atg7 and Atg3), allowing LC3B to associate with autophagic vesicles.[21] After autophagosomes are formed, they undergo a stepwise maturation process in which they engulf organelles, fuse with lysosomes, and mature into autolysosomes with lysosomal enzymes.[12] As shown in Fig. 1A and B, we examined the expression of LC3B mRNA and protein in BEAS-2B cells after exposure to HTT2800. Real-time PCR and western blot analysis showed that LC3B expression was increased in a dose-dependent manner. However, it remains unclear whether the endocytic and autophagic pathways are involved in HTT2800-mediated cell death. Our previous results suggested that HTT2800 caused cellular uptake of the carbon nanotube, increased cell death, enhanced DNA damage, and induced cytokine release.[6] However, the mechanism of cell death induction by HTT2800 remains unclear. As shown in Fig. 2A, our results show that HTT2800 caused the cell death of BEAS-2B cells in a doseand time-dependent manner. Next, we determined whether HTT2800 induced cell death by inhibiting autophagy. 3-MA is one of the most commonly used inhibitors in autophagosome formation. As shown in Fig. 3A, autophagy was detected by western blot analysis. HTT2800-induced LC3B-II protein was significantly decreased after treatment with 3-MA. We also monitored the cellular distribution of LC3B-II under fluorescence microscopy. The number of vacuoles was significantly lower than in HTT2800-treated cells (Fig. 3C and D). Furthermore, we determined the effects of brefeldin A on cellular autophagy. Brefeldin A inhibits the transport of proteins from the ER to the Golgi, while it induces protein transport from the Golgi to the ER. As shown in Fig. 3E, the effects of brefeldin A and 3-MA were examined; 3-MA, but not brefeldin A, reduced HTT2800-induced cell growth inhibition. We also examined the roles of lysosomal enzymes in the autophagic process; E-64d and pepstatin A provided protection and delayed HTT2800-induced cell growth inhibition. These results suggest that the effect of HTT2800 on BEAS-2B cells is mediated by a signaling pathway that upregulates the cellular autophagic capacity and promotes the activity of lysosomal proteases. Next, oxidative stress-induced caspase activation is a common event in apoptotic and non-apoptotic cell death.[22] In addition, pretreatment with the caspase inhibitor z-VAD-FMK had no significant protective effect on HTT2800-induced cell growth inhibition (Fig. 4A). Next, we examined the effect of HTT2800-mediated cell death by 3-MA. Caspase-3 is a key executioner of apoptosis,[23] and activation of caspase- 3 requires proteolytic processing into p17 and p12 fragments. Interestingly, we found that 3-MA-treated BEAS-3B cells were induced in caspase-3 activation (Fig. 4B). These results suggest that autophagy inhibition accelerates apoptosis in BEAS-2B cells. Furthermore, HTT2800induced autophagic cell death occurred in the absence of caspase activation and through an ROSindependent pathway (Fig. 4C). These results suggest that HTT2800 predominantly causes autophagy rather than apoptotic cell death in BEAS-2B cells. In summary, the mechanism of nanomaterialinduced autophagy accumulation in many cases remains unclear. Further studies are needed to clarify the molecular mechanisms underlying the interaction between nanomaterials and autophagy machinery.

\section{Acknowledgments}

This work was supported by research grants from the Astellas Foundation for Research on Metabolic

Disorders (to Tamotsu Tsukahara), Grant-in-Aid for Takeda Science Foundation (to Tamotsu 
Tsukahara) and JSPS KAKENHI Grant Numbers 25350524 (to Yuki Usui) and 25462365 (to Hisao Haniu).

\section{Conflict of Interest}

The authors have no financial conflicts of interest. 


\section{References}

[1] S. Vardharajula, S.Z. Ali, P.M. Tiwari, E. Eroglu, K. Vig, V.A. Dennis, S.R. Singh, Functionalized carbon nanotubes: biomedical applications, Int J Nanomedicine 7 (2012) 5361-5374.

[2] H. Haniu, N. Saito, Y. Matsuda, Y.A. Kim, K.C. Park, T. Tsukahara, Y. Usui, K. Aoki, M. Shimizu, N. Ogihara, K. Hara, S. Takanashi, M. Okamoto, N. Ishigaki, K. Nakamura, H. Kato, Elucidation mechanism of different biological responses to multi-walled carbon nanotubes using four cell lines, Int J Nanomedicine 6 (2011) 3487-3497.

[3] H. Haniu, N. Saito, Y. Matsuda, Y.A. Kim, K.C. Park, T. Tsukahara, Y. Usui, K. Aoki, M. Shimizu, N. Ogihara, K. Hara, S. Takanashi, M. Okamoto, N. Ishigaki, K. Nakamura, H. Kato, Effect of dispersants of multi-walled carbon nanotubes on cellular uptake and biological responses, Int J Nanomedicine 6 (2011) 3295-3307.

[4] H. Haniu, T. Tsukahara, Y. Matsuda, Y. Usui, K. Aoki, M. Shimizu, N. Ogihara, K. Hara, S. Takanashi, M. Okamoto, N. Ishigaki, K. Nakamura, H. Kato, N. Saito, DJ-1 as a potential biomarker for the development of biocompatible multiwalled carbon nanotubes, Int J Nanomedicine 6 (2011) 2689-2695.

[5] E. Flahaut, M.C. Durrieu, M. Remy-Zolghadri, R. Bareille, C. Baquey, Investigation of the cytotoxicity of CCVD carbon nanotubes towards human umbilical vein endothelial cells, Carbon 44 (2006) 1093-1099.

[6] T. Tsukahara, H. Haniu, Cellular cytotoxic response induced by highly purified multi-wall carbon nanotube in human lung cells, Mol Cell Biochem 352 (2011) 57-63.

[7] O. Zabirnyk, M. Yezhelyev, O. Seleverstov, Nanoparticles as a novel class of autophagy activators, Autophagy 3 (2007) 278-281.

[8] C. De Duve, The lysosome, Sci Am 208 (1963) 64-72.

[9] F. Reggiori, D.J. Klionsky, Autophagy in the eukaryotic cell, Eukaryot Cell 1 (2002) 11-21.

[10] B. Levine, J. Yuan, Autophagy in cell death: an innocent convict?, J Clin Invest 115 (2005) 26792688.

[11] P. Codogno, A.J. Meijer, Autophagy and signaling: their role in cell survival and cell death, Cell Death Differ 12 Suppl 2 (2005) 1509-1518.

[12] E.L. Eskelinen, P. Saftig, Autophagy: a lysosomal degradation pathway with a central role in health and disease, Biochim Biophys Acta 1793 (2009) 664-673. 
[13] B.J. Altman, J.C. Rathmell, Metabolic stress in autophagy and cell death pathways, Cold Spring Harb Perspect Biol 4 (2012) a008763.

[14] S.T. Stern, P.P. Adiseshaiah, R.M. Crist, Autophagy and lysosomal dysfunction as emerging mechanisms of nanomaterial toxicity, Part Fibre Toxicol 9 (2012) 20.

[15] H. Haniu, Y. Matsuda, K. Takeuchi, Y.A. Kim, T. Hayashi, M. Endo, Proteomics-based safety evaluation of multi-walled carbon nanotubes, Toxicol Appl Pharmacol 242 (2010) 256-262.

[16] E. Tasdemir, L. Galluzzi, M.C. Maiuri, A. Criollo, I. Vitale, E. Hangen, N. Modjtahedi, G. Kroemer, Methods for assessing autophagy and autophagic cell death, Methods Mol Biol 445 (2008) 29-76.

[17] B.T. Mossman, P.J. Borm, V. Castranova, D.L. Costa, K. Donaldson, S.R. Kleeberger, Mechanisms of action of inhaled fibers, particles and nanoparticles in lung and cardiovascular diseases, Part Fibre Toxicol 4 (2007) 4.

[18] M. Pacurari, X.J. Yin, J. Zhao, M. Ding, S.S. Leonard, D. Schwegler-Berry, B.S. Ducatman, D. Sbarra, M.D. Hoover, V. Castranova, V. Vallyathan, Raw single-wall carbon nanotubes induce oxidative stress and activate MAPKs, AP-1, NF-kappaB, and Akt in normal and malignant human mesothelial cells, Environ Health Perspect 116 (2008) 1211-1217.

[19] D. De Stefano, R. Carnuccio, M.C. Maiuri, Nanomaterials toxicity and cell death modalities, J Drug Deliv 2012 (2012) 167896.

[20] T. Yokoyama, J. Tam, S. Kuroda, A.W. Scott, J. Aaron, T. Larson, M. Shanker, A.M. Correa, S. Kondo, J.A. Roth, K. Sokolov, R. Ramesh, EGFR-targeted hybrid plasmonic magnetic nanoparticles synergistically induce autophagy and apoptosis in non-small cell lung cancer cells, PLoS One 6 (2011) e25507.

[21] Y. Kabeya, N. Mizushima, T. Ueno, A. Yamamoto, T. Kirisako, T. Noda, E. Kominami, Y. Ohsumi, T. Yoshimori, LC3, a mammalian homologue of yeast Apg8p, is localized in autophagosome membranes after processing, EMBO J 19 (2000) 5720-5728.

[22] V.J. Thannickal, B.L. Fanburg, Reactive oxygen species in cell signaling, Am J Physiol Lung Cell Mol Physiol 279 (2000) L1005-1028.

[23] A.G. Porter, R.U. Janicke, Emerging roles of caspase-3 in apoptosis, Cell Death Differ 6 (1999) 99-104. 


\section{Figure Legends}

Figure 1. HTT2800 induced LC3B protein and mRNA in BEAS-2B cells

(A) Representative western blot of LC3B-I and LC3B-II expression. Cells $\left(5 \times 10^{3}\right.$ cells/well) were seeded into 96-well culture plates for $24 \mathrm{~h}$. After $24 \mathrm{~h}$ of incubation with various concentrations of HTT2 800 or after treatment with $10 \mu \mathrm{g} / \mathrm{mL}$ of HTT2800 for the indicated times, whole-cell lysate (20 $\mu \mathrm{g}$ ) was analyzed using SDS-PAGE and visualized using enhanced chemiluminescence as described in the text. (B) Real-time PCR measurement of LC3B mRNA expression in BEAS-2B cells. Relative LC3B levels were normalized to $18 \mathrm{~S}$ rRNA and are expressed as the mean \pm standard error of the mean $(\mathrm{SEM})(\mathrm{n}=3 ; * * \mathrm{P}<0.01)$.

Figure 2. Concentration- and time-dependent effects of HTT2800 on the viability of BEAS-2B cells Cells $\left(5 \times 10^{3}\right.$ cells/well) were seeded in 96-well culture plates for $24 \mathrm{~h}$. The cell viability was determined using the Cell Counting Kit-8 after $24 \mathrm{~h}$ with various concentrations of HTT2800 (A) or after treatment with $10 \mu \mathrm{g} / \mathrm{mL}$ of HTT2800 for the indicated times (B).

Figure 3. Autophagy inhibitor 3-MA protected against HTT2800-induced cell death

(A) Whole cell lysate $(20 \mu \mathrm{g})$ was analyzed using SDS-PAGE and LC3B was visualized with enhanced chemiluminescence as described in the text. (B) Real-time PCR measurement of LC3B mRNA expression in BEAS-2B cells after treatment with or without 3-MA. Relative LC3B levels were normalized to $18 \mathrm{~S}$ rRNA and are expressed as the mean \pm standard error of the mean $(\mathrm{SEM})(\mathrm{n}=$ 3 ; **P $<0.01)$. (C) and (D) Autophagosome detection with Premo ${ }^{\mathrm{TM}}$ Autophagy Sensor. BEAS-2B cells were plated at $5 \times 10^{3}$ cells/well. Cells were then transduced with LC3B-GFP. Twenty-four hours later, the cells were incubated with $\operatorname{HTT} 2800(10,30$, and $100 \mu \mathrm{M})$ for $24 \mathrm{~h}$. Analysis was performed by quantifying the florescence from vesicular structures in the perinuclear region using the Keyence fluorescent microscope BIOREVO BZ-9000. (E) The survival of HTT2800-treated cells in the presence and absence of the indicated compounds were measured using the Cell Counting Kit-8. Cells $\left(5 \times 10^{3}\right.$ cells/well) were seeded into 96-well culture plates for $24 \mathrm{~h}$. Cells were pretreated for $2 \mathrm{~h}$ with 3-MA $(100 \mu \mathrm{M})$, E64-d+pepstatin A $(10 \mu \mathrm{M}$ each) or brefeldin A $(20 \mu \mathrm{M})$ prior to exposure to HTT2800. Cells were pretreated for $2 \mathrm{~h}$ with compounds prior to coexposure to inhibitor and HTT2800 for $24 \mathrm{~h}$. Data are expressed as the mean $\pm \operatorname{SEM}(n=4 ; * * \mathrm{P}<0.01)$.

Figure 4. Effects of z-VAD-FMK on HTT2800-mediated autophagy in BEAS-2B cells

(A) Following 2-h pretreatment with z-VAD-FMK, BEAS-2B cells were coexposed to HTT2800 for $24 \mathrm{~h}$. The effects of $\mathrm{z}-\mathrm{VAD}-\mathrm{FMK}$ on the survival of HTT2800-treated cells were measured using the Cell Counting Kit-8. Data are expressed as the mean \pm SEM $(n=4 ; * * P<0.01)$. (B) Whole-cell lysate $(20 \mu \mathrm{g})$ was analyzed using SDS-PAGE and casapase-3 was visualized with enhanced chemiluminescence as described in the text. (C) Intracellular production of ROS in BEAS-2B cells treated with HTT2800. BEAS-2B cells were incubated for 60 min without HTT2800 (negative control) or with $10 \mu \mathrm{g} / \mathrm{mL}$ of HTT2800 and stained with C-400. Fluorescent intensity was monitored by flow cytometry. Intracellular generation of ROS is expressed as the percentage of control. Hydrogen peroxide $(1 \mathrm{mM})$ was used as a positive control. Bars indicate the mean \pm SEM of two independent experiments. 

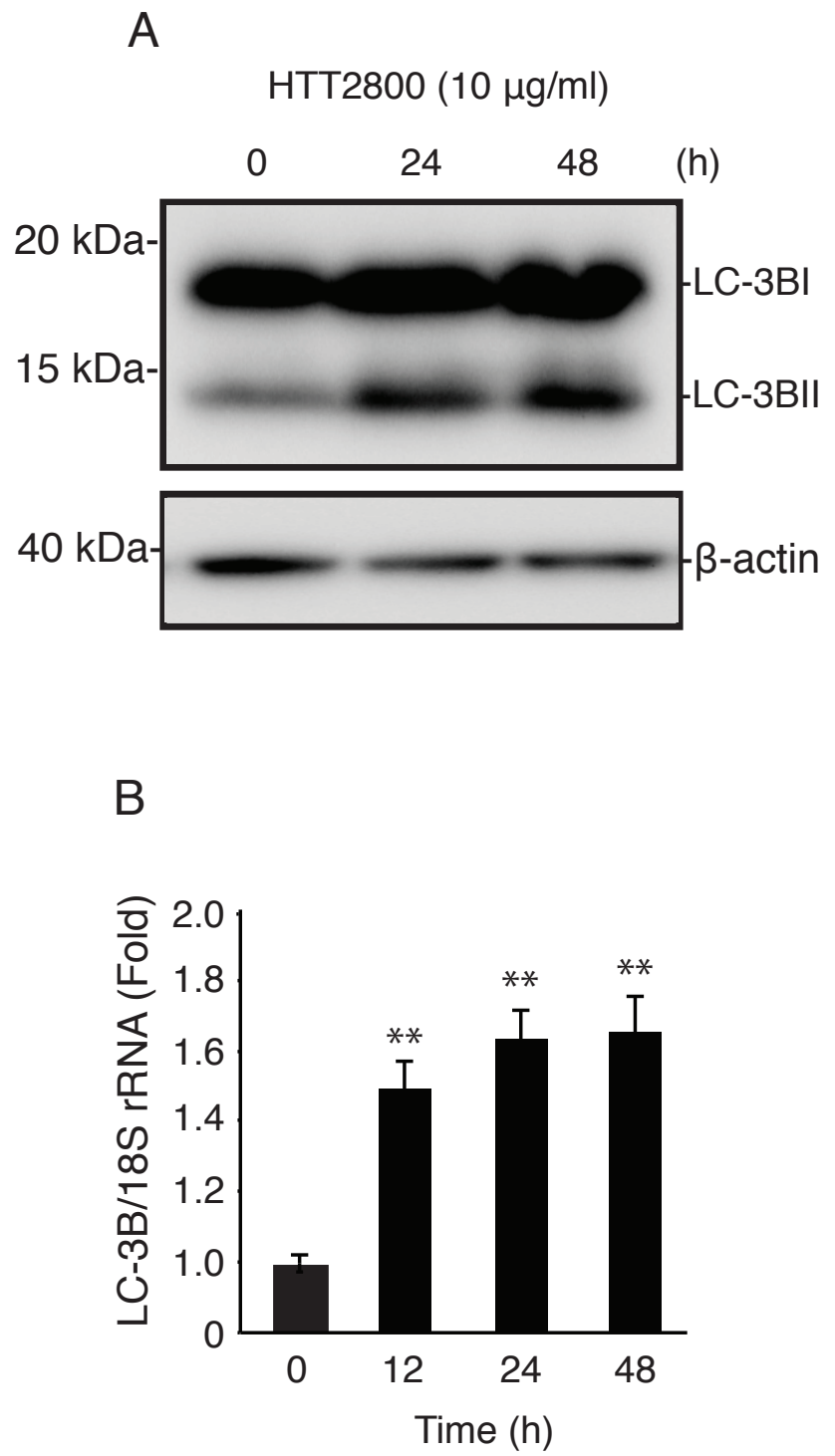

Fig.1 

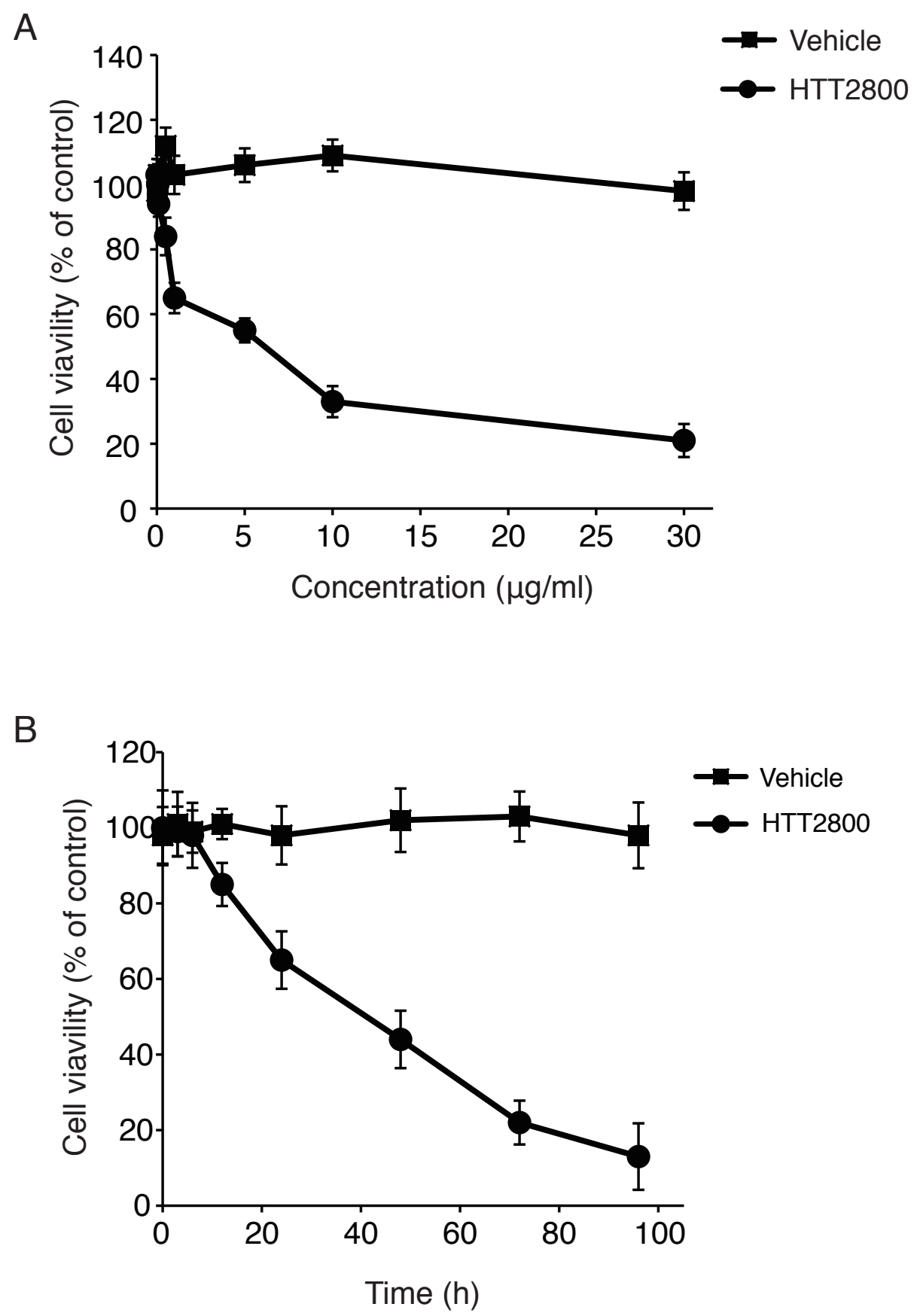

Fig.2 
A

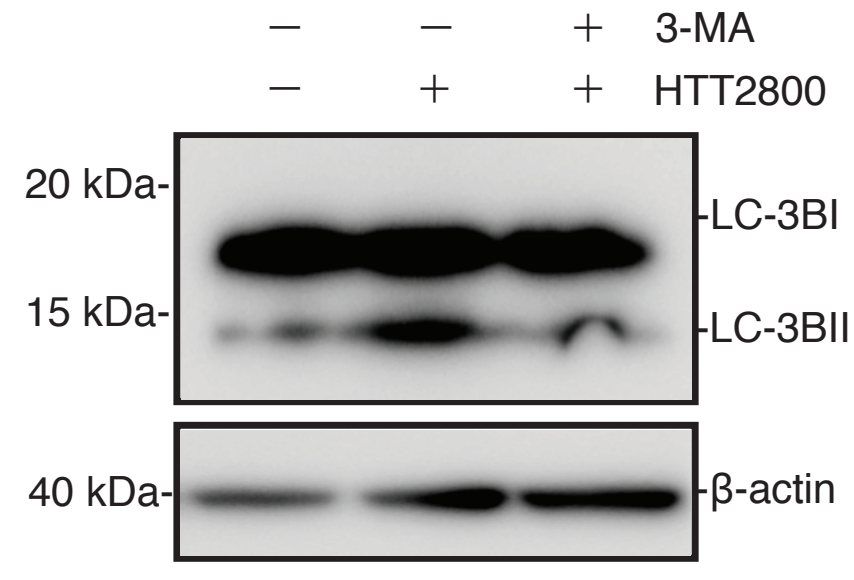

C

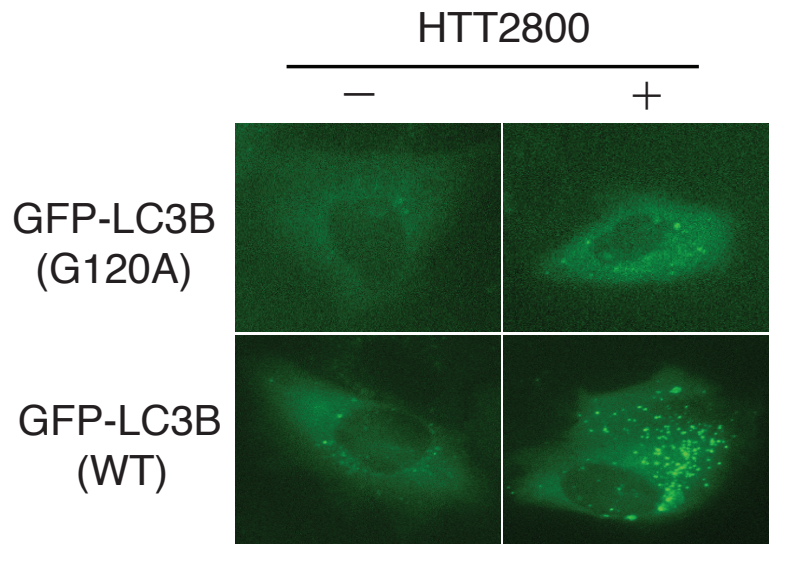

E

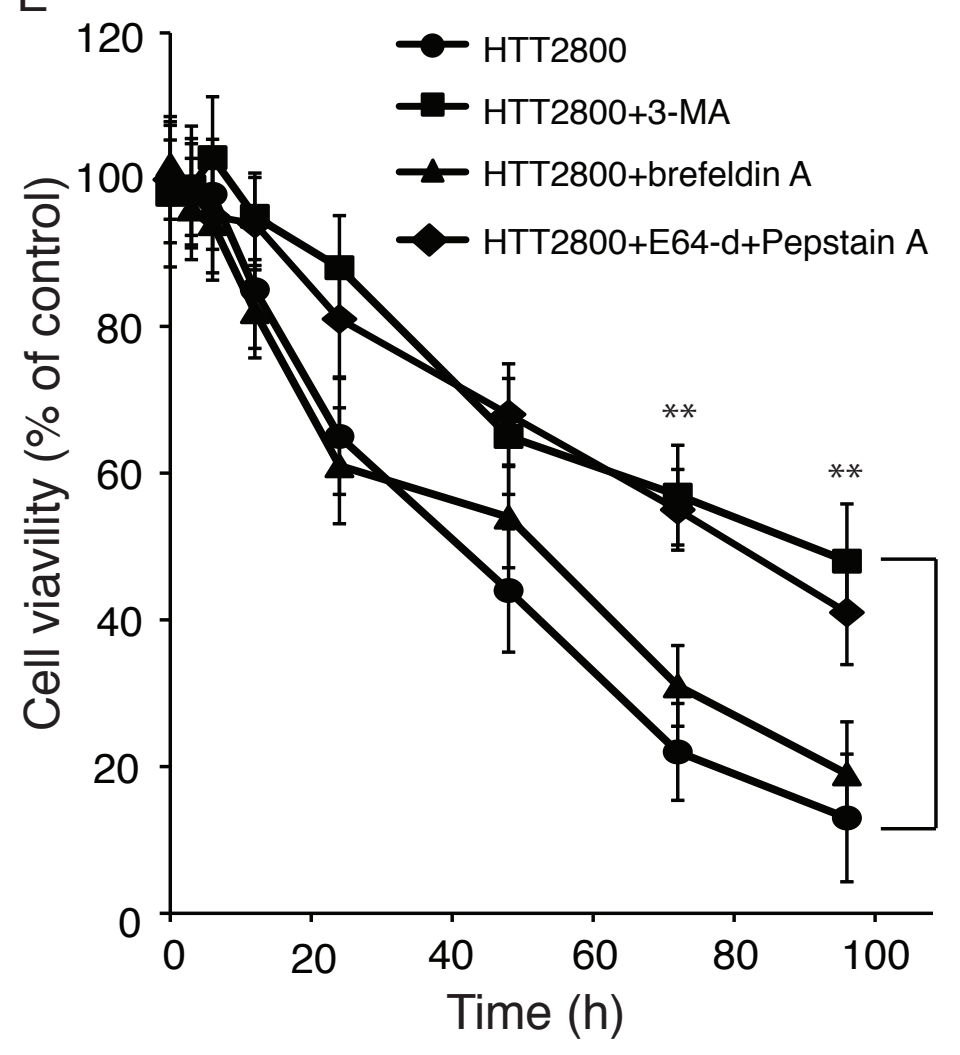

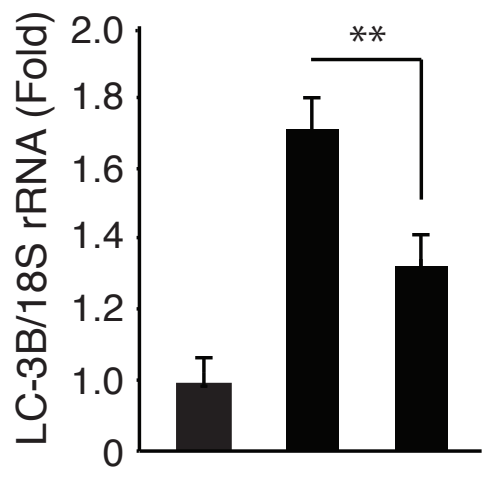

3-MA $\quad-\quad-\quad+$ НTT2800 - ++

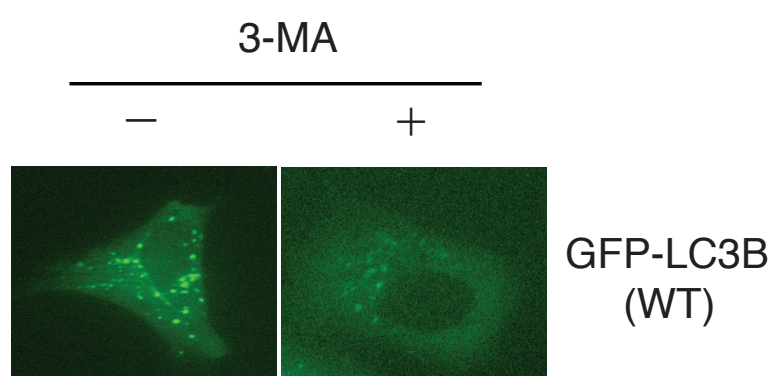

Fig.3 
A

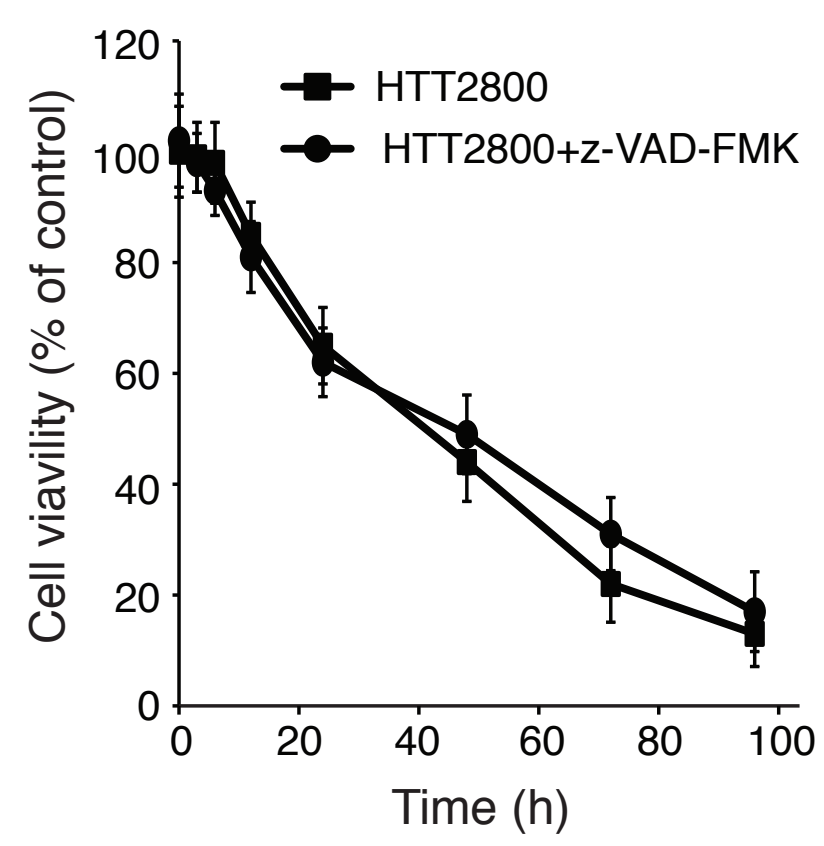

B

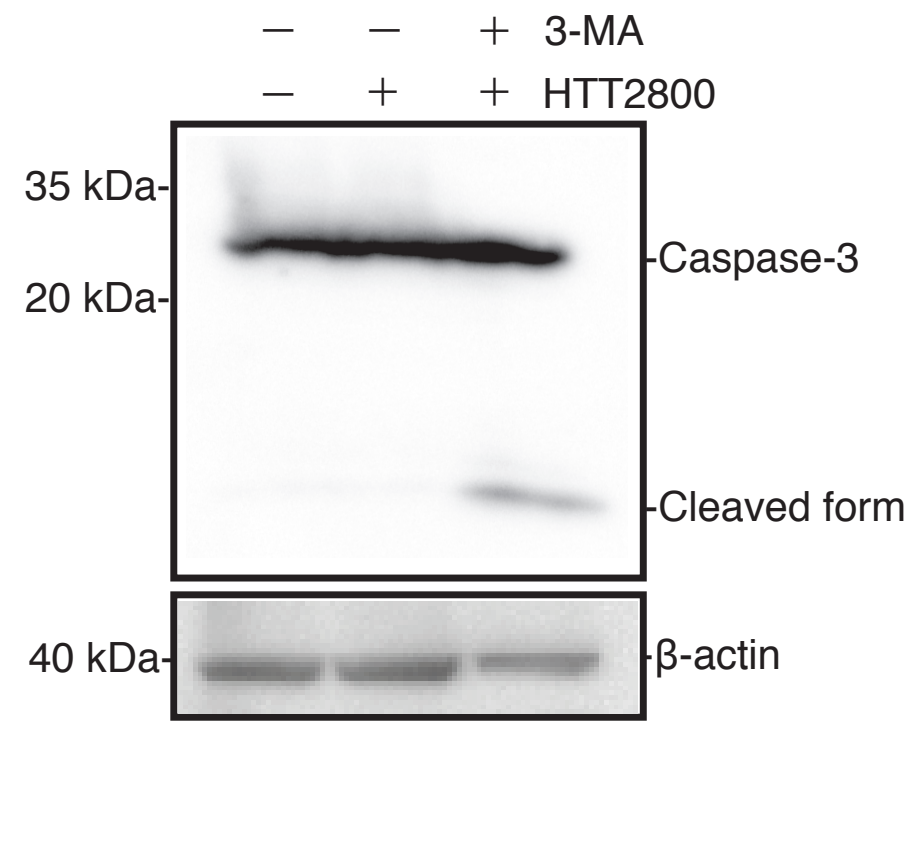

C

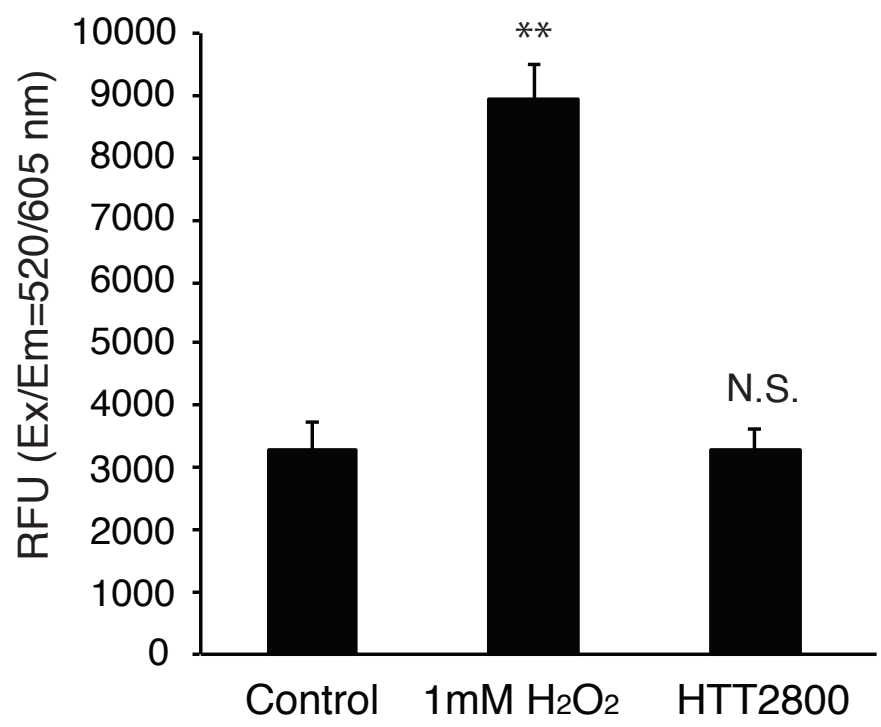

Fig.4 